\title{
Prevalence of chronic kidney disease and associated risk factors among diabetic patients in southern Ethiopia
}

\author{
Temesgen Fiseha ${ }^{1, *}$, Mehidi Kassim ${ }^{2}$, Tilahun Yemane ${ }^{3}$ \\ ${ }^{1}$ Department of Clinical Laboratory Science, College of Public Health and Medical Sciences, Jimma University, Ethiopia \\ ${ }^{2}$ Department of Biochemistry, College of Public Health and Medical Sciences, Jimma University, Ethiopia \\ ${ }^{3}$ Department of Hematology, College of Public Health and Medical Sciences, Jimma University, Ethiopia
}

\section{Email address:}

temafiseha@gmail.com (T. Fiseha),mehidikia@yahoo.com (M. Kassim), yemanetilahun@yahoo.com (T. Yemane)

\section{To cite this article:}

Temesgen Fiseha, Mehidi Kassim, Tilahun Yemane. Prevalence of Chronic Kidney Disease and Associated Risk Factors among Diabetic Patients in Southern Ethiopia. American Journal of Health Research. Vol. 2, No. 4, 2014, pp. 216-221. doi: 10.11648/j.ajhr.20140204.28

\begin{abstract}
Background: Chronic kidney disease (CKD) in diabetes is associated with an increased risk of premature mortality, kidney failure and cardiovascular disease. No studies are available on the prevalence of CKD among diabetics in Ethiopia. The aim of this study was to determine the prevalence of CKD and its associated risk factors among diabetic adults attending Butajira hospital of Southern Ethiopia based on estimated glomerular filtration rate (GFR). Methods: A facility based cross sectional study was conducted in Butajira hospital, southern Ethiopia among 214 randomly selected diabetic adults. Demographic, clinical, and laboratory data were collected from September 1, 2013 to October $31,2013$. The simplified Modification of Diet in Renal Disease (MDRD) and Cockroft-Gault (CG) equations were used to estimate GFR (eGFR) from serum creatinine value. SPSS 20.0 Software was used for data analysis. Results: 39 (18.2\%) and 51 $(23.8 \%)$ of the study participants were found to have CKD, as defined by eGFR $<60 \mathrm{ml} / \mathrm{min} / 1.73 \mathrm{~m}^{2}$, according to the MDRD and Cockroft-Gault equations, respectively. Of these; 17.3 and $22.9 \%$ have stage 3 CKD, and $0.9 \%$ have stage 4 CKD, respectively. Significant risk factors for CKD in the study subjects when using either the MDRD or C-G equation were older age, longer duration of diabetes, family history of kidney disease, and poor glucose control $(\mathrm{P}<0.05)$. Additionally, female sex $(\mathrm{P}<0.008)$ and obesity $(\mathrm{P}<0.038)$ were independent risk factors for $\mathrm{CKD}$ when defined by the MDRD, and type 2 diabetes was when defined by $\mathrm{C}-\mathrm{G}(\mathrm{P}<0.03)$. Conclusion: $\mathrm{CKD}$ was present in not less than $18.2 \%$ diabetic adults attending the follow up clinic at Butajira hospital, in southern Ethiopia. Risk factors for CKD were similar to those reported in developed country studies. Using the MDRD equation led to a lower prevalence of CKD and a better risk categorization than did by $\mathrm{C}-\mathrm{G}$ equation, thus contributing to better management of clinical outcomes in diabetic care.
\end{abstract}

Keywords: Chronic Kidney Disease, Diabetes, Risk Factors, Estimated Glomerular Filtration Rate

\section{Introduction}

Chronic kidney disease (CKD) is a world-wide public health problem associated with adverse outcomes of kidney failure, cardiovascular disease (CVD), and premature death [1]. It has been estimated that more than 500 million individuals globally have $\mathrm{CKD}$, defined by either kidney damage or glomerular filtration rate (GFR) $<60$ $\mathrm{ml} / \mathrm{min} / 1.73 \mathrm{~m}^{2}$ for $\geq 3$ months, regardless of the cause $[2,3]$. Diabetes is a major public health problem around the world, estimated to affect more than 371 million people in 2012, and is the leading cause of end stage renal disease (ESRD) in both developed and emerging nations [4,5].

The risk of all cause and cardiovascular mortality, kidney failure, cardiovascular disease and hospitalizations is higher among diabetic patients with $\mathrm{CKD}$, as defined by estimated GFR (eGFR) $<60 \mathrm{ml} / \mathrm{min} / 1.73 \mathrm{~m}^{2}$, than among those with normal renal function [6-8]. Additionally, affected patients have an increased risk of complications, such as hypertension, anemia, malnutrition, bone and mineral disorders, retinopathy and neuropathy, and thus suffer extra morbidity and mortality $[9,10]$. There is also an even higher prevalence of hypoglycemia due to decreased clearance of antidiabetic agents or impaired renal gluconeogenesis, and progressive renal dysfunction reduces drug elimination and prolongs exposure to higher drug levels [11]. 
Routine screening for CKD based on estimated GFR (eGFR) derived from serum creatinine measurements is recommended for diabetes care [12], as reduced eGFR is an independent predictor of cardiovascular and renal events and mortality in people with diabetes [6,8]. Furthermore, given that CKD (defined as eGFR $<60 \mathrm{ml} / \mathrm{min} / 1.73 \mathrm{~m}^{2}$ ) is often not detected until it is advanced, targeted screening of diabetes based on eGFR is cost effective and has potential benefits, such as early identification and treatment of affected patients [13].

Although estimating the prevalence of $\mathrm{CKD}$ combined with identification and treatment of risk factors is central to disease management and prevention planning, there are virtually no published studies on the prevalence and risk factors of CKD among diabetic patients in Ethiopia. Thus, the aim of this study was to estimate the prevalence of CKD among diabetic adults attending Butajira hospital of Southern Ethiopia, and to identify the associated risk factors based on eGFR derived from the MDRD Study and Cockcroft-Gault equations.

\section{Materials and Methods}

A facility based across sectional study was conducted in Butajira hospital of Southern Ethiopia over a period of two months (September 2013 to October 2013). The hospital is located in Butajira town, $130 \mathrm{~km}$ mid-south of the capital of Ethiopia, Addis Ababa. The hospital registers and treats all diagnosed diabetic patients and provides primary diabetes patient care.

The study was conducted among two hundred fourteen randomly selected diabetic patients who were registered at the follow up clinic of Butajira hospital. Participants, who were included in this study after being screened and counseled by their clinicians, were adults ( $\geq 18$ years) and attending the hospital for follow up. Exclusion criteria were pregnancy, hospitalization, acute illnesses (fever), and none fasting. Patients found to have eGFR $>200 \mathrm{ml} / \mathrm{min} / 1.73 \mathrm{~m}^{2}$ or those receiving dialysis were also excluded.

The study participants underwent interview for collecting demographic and risk factor variables using a structured questionnaire designed by the investigators. Physical examinations, including measurement of height, weight and blood pressure were performed. Weight $(\mathrm{kg})$ and height (meters) were assessed in light clothing without shoes and body mass index (BMI) was calculated as weight divided by height squared $\left(\mathrm{kg} / \mathrm{m}^{2}\right)$. Obesity was defined as a BMI $\geq 30 \mathrm{~kg} / \mathrm{m}^{2}$. Blood pressure was measured three times using a standard mercury sphygmomanometer after 5 min of rest in sitting position and then averaged. Systolic blood pressure $\geq 140 \mathrm{mmHg}$ and/or diastolic blood pressure $\geq 90 \mathrm{mmHg}$ or current use of blood pressure-lowering medication was used to define hypertension.

\subsection{Laboratory Measurements and Definitions}

A fasting blood sample was collected from each participant using standard venipuncture techniques and biochemical analysis were performed using HumaStar 80 analyzer (Human Diagnostics, Germany). Serum glucose levels were measured using the enzymatic GOD-PAP method (Human Diagnostics, Germany). Serum creatinine was measured by kinetic alkaline picrate method (Human Diagnostics, Germany) with calibration traceable to reference material NIST SRM 909B level 2.

The GFR was estimated using the Modification of Diet in Renal Disease (MDRD) Study equation [14]: $186 \times$ [serum creatinine $(\mathrm{mg} / \mathrm{dl})]^{-1.154} \times(\text { age })^{-0.203} \times(0.742$ if female) x (1.210, if African American), and Cockcroft-Gault formula[15] (normalized for the body surface area [BSA]): $(140$ - age [years]) $\mathrm{x}$ weight $(\mathrm{kg}) \mathrm{x}(0.86$, if female $) \mathrm{x}$ $1.73 / 72 \times$ serum creatinine $(\mathrm{mg} / \mathrm{dl}) \times$ BSA $\left(\mathrm{m}^{2}\right)$.

All the participants with eGFR values of $<60$ $\mathrm{ml} / \mathrm{min} / 1.73 \mathrm{~m}^{2}$ screened at the $1 \mathrm{st}$ visit were advised to have their serum checked for creatinine two weeks after the first check-up. The CKD stages were categorized based on the classification system established by the National Kidney Foundation - Kidney Disease Outcomes Quality Initiative (K/DOQI) classification. For the purposes of this study, CKD was defined as K/DOQI CKD stages 3-5 $\left(\right.$ eGFR $\left.<60 \mathrm{ml} / \mathrm{min} / 1.73 \mathrm{~m}^{2}\right)$ : with eGFR 30-59, 15-29 and $<15 \mathrm{ml} / \mathrm{min} / 1.73 \mathrm{~m}^{2}$, respectively. Stage 3 was further classified into 3A (45-59.9) and 3B (30-44.9)[3,16].

\subsection{Statistical Analysis}

The data was entered in to "EpiInfo version 3.1" and was analyzed using SPSS version 20.0 statistical software. Normally distributed variables are summarized by their means and SDs, median and range are used for skewed data. Chi-square $\left(\mathrm{x}^{2}\right)$ analysis was used for between-group comparisons of CKD proportions. Multivariate stepwise logistic regression was performed by including variables that were significant at $P$ value $<0.02$. Adjusted odds ratio (AOR) and their corresponding 95\% confidence intervals (CI) were expressed to describe the association of risk factors with CKD (dependent variable). For all statistical analyses $P$ value $<0.05$ were considered significant.

\subsection{Ethical Consideration}

The ethical issue of this study was approved by the Ethical Committee of the college of Public Health and Medical Sciences, Jimma University. All participants were given detail information about the objective and purpose of the study and verbal consent was obtained from each participant.

\section{Results}

\subsection{Demographic and Clinical Characteristics of Participants}

For the included two hundred fourteen eligible diabetic participants, demographic, clinical, and laboratory data were collected between September 1, 2013 and October 31, 2013. The mean age of participants was $45 \pm 14.5$ years. Of 
the total participants, $81.3 \%$ were less than 60 years old; $57.5 \%$ were males and $56.3 \%$ had type 2 diabetics. Mean body mass index (BMI) was $25.26 \pm 4.35 \mathrm{Kg} / \mathrm{m}^{2}$. Mean values for systolic and diastolic BP were $121 \pm 17$ and $79 \pm$ $10 \mathrm{mmHg}$, respectively. Mean fasting serum glucose was $172.85 \pm 84.94 \mathrm{mg} / \mathrm{dl}$. Mean serum creatinine was $1.07 \pm$ $0.33 \mathrm{mg} / \mathrm{dl}$. The mean GFR values estimated according to the MDRD and C-G equations were $96.70 \pm 35.68$ and $83.61 \pm 29.73 \mathrm{ml} / \mathrm{min} / 1.73 \mathrm{~m}^{2}$, respectively.

\subsection{Prevalence of CKD}

Of the total participants, the estimated prevalence of CKD, defined by eGFR $<60 \mathrm{ml} / \mathrm{min} / 1.73 \mathrm{~m}^{2}$, in this study was $18.2 \%$ (CI 95\% $=12.3 \%-23.2 \%$ ) and $23.8 \%$ (CI 95\% $=17.5 \%-29.9 \%$ ) when defined by according to the MDRD and C-G equations, respectively. By stages, the prevalence was; $17.3 \%$ with stage 3 CKD (14.0\% stage $3 \mathrm{~A}$ and $3.3 \%$ stage $3 \mathrm{~B}$ ), and $0.9 \%$ with stage 4 CKD by MDRD; whereas $22.9 \%$ with stage $3(15.0 \%$ stage $3 \mathrm{~A}$ and $7.9 \%$ stage $3 \mathrm{~B}$ ) and $0.9 \%$ with stage 4 by $\mathrm{C}-\mathrm{G}$ (Table 1 ).

Table 1. Prevalence of CKD according to the MDRD and Cockcroft-Gault equations $(n=214)$.

\begin{tabular}{lllll}
\hline Stage & Description & eGFR $\left(\mathbf{m l} / \mathbf{m i n} / \mathbf{1 . 7 3 \mathbf { m } ^ { 2 } )}\right.$ & MDRD N (\%) & Cockcroft-Gault N (\%) \\
\hline $0-2$ & CKD absent & $\geq 60$ & $175(81.8)$ & $163(76.2)$ \\
$3-5$ & CKD present & $<60$ & $39(18.2)$ & $51(23.8)$ \\
3 & Moderate $\downarrow$ GFR & $30-59.9$ & $37(17.3)$ & $49(22.9)$ \\
3A & Mild to moderate GFR & $45-59.9$ & $30(14.0)$ & $32(15.0)$ \\
$3 B$ & Moderate to severe $\downarrow$ GFR & $30-44.9$ & $7(3.3)$ & $17(7.9)$ \\
4 & Severe $\downarrow$ GFR & $15-29.9$ & $2(0.9)$ & $2(0.9)$ \\
\hline
\end{tabular}

By age group, CKD prevalence was significantly higher among participants $>60$ years old than $\leq 60$ years old: $42.9 \%$ vs. $14.5 \%(p<0.001)$ and $64.3 \%$ vs. $17.7 \%(p<$ 0.001 ) according to the MDRD and $\mathrm{C}-\mathrm{G}$ equations, respectively. CKD prevalence was higher in females than males: $28.6 \%$ vs. $10.6 \%$ by MDRD $(P=0.001)$, and $31.9 \%$ vs. $7.0 \%$ by $\mathrm{C}-\mathrm{G}(P=0.018)$. The prevalence was also significantly higher among type 2 diabetic participants than type $1: 28.1 \%$ vs. $17.9 \%$ by MDRD $(P<0.001)$, and $37.7 \%$ vs. $8.0 \%$ by $\mathrm{C}-\mathrm{G}(P<0.001)$ (Table 2$)$.

Longer duration of diabetes, defined as duration more than 10 years, was reported in $31.8 \%$ of the participants and was associated with a high prevalence of CKD $(32.4 \%$ and $39.7 \%$ ) compared to shorter duration: $32.4 \%$ vs. $11.6 \%$ by MDRD $(P<0.001)$, and $39.7 \%$ vs. $16.4 \%$ by $\mathrm{C}-\mathrm{G}(P<$ $0.001)$. CKD prevalence was significantly higher among participants with low monthly income $<500$ ETB than those with $\geq 500$ ETB: $36.1 \%$ vs. $12.6 \%$ by MDRD $(P=0.005)$, and $35.4 \%$ vs. $17.0 \%$ by C-G $(P=0.002)$. However, there were no significant differences in CKD prevalence among participants with and without current smokers, and among those with less than high school and high school or higher education levels (Table 2).

Family history of kidney disease (FH-KD), present in $18.7 \%$ of participants, was associated with a higher prevalence of CKD than its absence: $42.5 \%$ vs. $12.6 \%$ by MDRD $(P<0.001)$, and $55.0 \%$ vs. $16.7 \%$ by C-G $(P<0.001)$. Furthermore, obesity that was reported in $14.5 \%$ of participants was associated with a high prevalence of CKD compared with lack of obesity: $45.2 \%$ vs. $13.7 \%$ by MDRD $(P<0.001)$, and $45.2 \%$ vs. $20.2 \%$ by $\mathrm{C}-\mathrm{G}(P=0.003)$ (Table 2).

Hypertension, reported in $58.2 \%$ of the total participants, was not associated with a high proportion of CKD; however, elevated systolic blood pressure $(\geq 140 \mathrm{mmHg})$ was associated with a higher prevalence of CKD: $30.0 \%$ vs.
$15.5 \%$ by MDRD $(P=0.032)$, and $42.5 \%$ vs. $19.5 \%$ by C$\mathrm{G}(P=0.002)$. Uncontrolled diabetes associated with high fasting serum glucose (FSG), defined as FSG level $\geq 150$ $\mathrm{mg} / \mathrm{dl}$, was found in $60.3 \%$ of participants and was associated with higher prevalence of CKD $(24.0 \%$ and $31.0 \%$ ) compared with controlled diabetes: $24.0 \%$ vs. $9.4 \%$ by MDRD $(P=0.007)$, and $31.0 \%$ vs. $12.9 \%$ by C-G $(P$ $=0.002)$ (Table 2$)$.

Table 2. Distribution of CKD by characteristics of study participants using the MDRD and Cockcroft-Gault equations $(n=214)$.

\begin{tabular}{|c|c|c|c|c|c|}
\hline \multirow{2}{*}{ Variables } & \multirow{2}{*}{$\mathbf{N}$} & \multicolumn{2}{|l|}{ MDRD } & \multicolumn{2}{|c|}{ Cockcroft-Gault } \\
\hline & & $\%$ CKD & $P$ & $\%$ CKD & $P$ \\
\hline Age & & & $<0.001$ & & $<0.001$ \\
\hline$>60$ Year & 40 & 42.9 & & 64.3 & \\
\hline$\leq 60$ Years & 174 & 14.5 & & 17.7 & \\
\hline Sex & & & 0.001 & & 0.018 \\
\hline Male & 123 & 10.6 & & 17.9 & \\
\hline Female & 91 & 28.6 & & 31.9 & \\
\hline Types of diabetes & & & $<0.001$ & & $<0.001$ \\
\hline Type 1 & 100 & 7.0 & & 8.0 & \\
\hline Type 2 & 114 & 28.1 & & 37.7 & \\
\hline Duration of diabetes & & & $<0.001$ & & $<0.001$ \\
\hline$\geq 10$ years & 68 & 32.4 & & 39.7 & \\
\hline$<10$ years & 146 & 11.6 & & 16.4 & \\
\hline Education & & & 0.164 & & 0.283 \\
\hline$<$ High School & 169 & 20.1 & & 25.4 & \\
\hline$\geq$ High School & 45 & 11.1 & & 17.8 & \\
\hline Income & & & 0.005 & & 0.002 \\
\hline$<500 \mathrm{ETB}$ & 79 & 27.8 & & 35.4 & \\
\hline$\geq 500 \mathrm{ETB}$ & 135 & 12.6 & & 17.0 & \\
\hline $\begin{array}{l}\text { Family history of } \\
\text { KD }\end{array}$ & & & $<0.001$ & & $<0.001$ \\
\hline Present & 40 & 42.5 & & 55.0 & \\
\hline Absent & 174 & 12.6 & & 16.7 & \\
\hline Smoking status & & & 0.310 & & 0.461 \\
\hline $\begin{array}{l}\text { Current } \\
\text { Smokers }\end{array}$ & 13 & 7.7 & & 15.4 & \\
\hline Non Smokers & 201 & 18.9 & & 24.4 & \\
\hline Obesity & & & $<0.001$ & & 0.003 \\
\hline Present & 31 & 45.2 & & 45.2 & \\
\hline
\end{tabular}




\begin{tabular}{llllll}
\hline Variables & \multirow{2}{*}{$\mathbf{N}$} & MDRD & \multicolumn{2}{c}{ Cockcroft-Gault } \\
\cline { 3 - 6 } & \%CKD & $\boldsymbol{P}$ & \%CKD & $\boldsymbol{P}$ \\
\hline Absent & 183 & 13.7 & & 20.2 & \\
$\begin{array}{l}\text { Hypertension } \\
\quad \text { Present }\end{array}$ & 113 & 17.7 & & 24.5 & \\
$\quad$ Absent & 101 & 18.8 & & 22.8 & \\
$\begin{array}{l}\text { Systolic blood } \\
\text { pressure }\end{array}$ & & & 0.032 & & 0.002 \\
$\quad \geq 140 \mathrm{mmHg}$ & 40 & 30.0 & & 42.5 & \\
$\quad<140 \mathrm{mmHg}$ & 174 & 15.5 & & 19.5 & \\
$\begin{array}{l}\text { Diastolic blood } \\
\text { pressure }\end{array}$ & & & 0.434 & & 0.092 \\
$\quad \geq 90 \mathrm{mmHg}$ & 45 & 22.2 & & 33.3 & \\
$\quad<90 \mathrm{mmHg}$ & 169 & 17.2 & & 21.3 & \\
$\begin{array}{l}\text { Fasting Serum } \\
\text { Glucose }\end{array}$ & & & 0.007 & & 0.002 \\
$\quad \geq 150 \mathrm{mg} / \mathrm{dl}$ & 129 & 24.0 & & 31.0 & \\
$\quad<150 \mathrm{mg} / \mathrm{dl}$ & 85 & 9.4 & & 12.9 & \\
\hline
\end{tabular}

\subsection{Risk Factors Associated with CKD}

The univariate analysis showed significant association between CKD (eGFR $<60 \mathrm{ml} / \mathrm{min} / 1.73 \mathrm{~m}^{2}$ ) and the following variables; older age ( $>60$ years), female gender, type 2 diabetes, low monthly income, longer duration of diabetes, family history of kidney disease, elevated systolic blood pressure, obesity, high FSG. After incorporating all significant $(p<0.20)$ variables in the univariate analysis, multivariate logistic regression was performed to identify risk factors independently associated with CKD.

In multivariate analysis, older age (adjusted $\mathrm{OR}=5.30$, CI 1.81-15.56), female sex (adjusted $\mathrm{OR}=3.34$, CI 1.388.10 ), longer duration of diabetes (adjusted $\mathrm{OR}=4.08, \mathrm{CI}$ 1.70-9.77), family history of kidney disease (adjusted $\mathrm{OR}=$ 3.16, CI 1.29-7.77), obesity (adjusted OR $=2.75$, CI 1.017.51 ) and poor glucose control (high FSG) (adjusted OR = 4.65, CI 1.69-12.76) were independently associated with CKD when defined by the MDRD equation. All the above variables, except sex and obesity, were independently associated with CKD when renal function was defined by C-G. Additionally, type 2 diabetes (adjusted $\mathrm{OR}=2.86$, CI 1.11-7.39) was found to be independently associated with CKD when C-G equation was used (Table 3).

Table 3. Risk factors associated with CKD according to the MDRD and Cockcroft-Gault equations $(n=214)$.

\begin{tabular}{|c|c|c|c|c|c|}
\hline \multirow{2}{*}{ Risk Factors } & & \multicolumn{2}{|l|}{ MDRD equation } & \multicolumn{2}{|l|}{ Cockcroft-Gault equation } \\
\hline & & Adjusted OR (95\% CI) & $P$ & Adjusted OR (95\% CI) & $P$ \\
\hline \multirow{2}{*}{ Age } & $\leq 60$ years & 1.00 & & 1.00 & \\
\hline & $>60$ years & $5.30(1.81-15.56)$ & 0.002 & $11.40(3.97-32.78)$ & $<0.001$ \\
\hline \multirow{2}{*}{ Sex } & Males & 1.00 & & 1.00 & \\
\hline & Females & $3.34(1.38-8.10)$ & 0.008 & $2.28(0.97-5.37)$ & 0.058 \\
\hline \multirow{2}{*}{ Types of diabetes } & Type 1 & 1.00 & & 1.00 & \\
\hline & Type 2 & $0.46(0.16-1.23)$ & 0.141 & $2.86(1.11-7.39)$ & 0.030 \\
\hline \multirow{2}{*}{ Duration of diabetes } & $<10$ years & 1.00 & & 1.00 & \\
\hline & $\geq 10$ years & $4.08(1.70-9.77)$ & 0.002 & $3.57(1.51-8.41)$ & 0.004 \\
\hline \multirow{2}{*}{ FH-KD } & Absent & 1.00 & & 1.00 & \\
\hline & Present & $3.16(1.29-7.77)$ & 0.012 & $4.12(1.79-10.88)$ & 0.001 \\
\hline \multirow{2}{*}{ Obesity } & No & 1.00 & & 1.00 & \\
\hline & Yes & $2.75(1.01-7.51)$ & 0.038 & $1.22(0.43-3.50)$ & 0.710 \\
\hline \multirow{2}{*}{ FSG } & $\leq 150 \mathrm{mg} / \mathrm{dl}$ & 1.00 & & 1.00 & \\
\hline & $>150 \mathrm{mg} / \mathrm{dl}$ & $4.65(1.69-12.76)$ & 0.003 & $3.66(1.43-9.35)$ & 0.007 \\
\hline
\end{tabular}

FH-KD $=$ Family history of kidney disease. $\mathrm{FSG}=$ Fasting Serum Glucose.

\section{Discussion}

Although several studies in developed countries show a high prevalence of CKD among patients with diabetes, this study was the first to assess the prevalence and risk factors of CKD among diabetic adults in Ethiopia with the use of estimated GFR derived from serum creatinine and estimating equations. The prevalence of CKD (eGFR $<60$ $\mathrm{ml} / \mathrm{min} / 1.73 \mathrm{~m}^{2}$ ) was $18.2 \%$ using the MDRD study and $23.8 \%$ by $\mathrm{C}-\mathrm{G}$ equations; CKD stage 3 was the most prevalent stage, 17.3 and $22.9 \%$ by both the MDRD and CG, respectively.

Our prevalence estimate of CKD using the MDRD equations was higher than $15.1 \%$ reported in the US NHANES III study [17], but lower than that of $27.5 \%$ and $31 \%$ reported in two UK studies $[18,19]$, and $33.1 \%$ in Japanese study [20]. These differences in CKD prevalence might be because of the differences in case-mix or differences in creatinine assays and calibration, or due to the incorporation of a 0.808 coefficient to the MDRD equation for Japanese population.

When using the $\mathrm{C}-\mathrm{G}$ equation to assesses renal function, our prevalence estimate of CKD was comparable to the Sub-Sahara African, Tanzania study which reported 24.7\% of patients with diabetes as having CKD as defined by eGFR $<60 \mathrm{ml} / \mathrm{min} / 1.73 \mathrm{~m}^{2}$; with $20.9 \%$ stage 3 CKD [21]. When looking at the prevalence of CKD estimated by the MDRD equation versus by $\mathrm{C}-\mathrm{G}$ equation, the MDRD tends to underestimate this prevalence in comparison with $\mathrm{C}-\mathrm{G}$, though the difference was not statistically significant.

As for risk factors, this study found a significant association between older age and CKD whatever the equations were used. This is consistent with findings from other studies $[19,20,22,23]$. It was reported that the eGFR diminishes with age, and at age $\geq 60$ years; $25 \%$ of the diabetics will have eGFR $<60 \mathrm{~mL} / \mathrm{min} / 1.73 \mathrm{~m}^{2}$ (24). Thus, to screen diabetics in this age group is an important strategy for the detection of CKD and to improve the outcomes. 
Gender differences have a significant association with $\mathrm{CKD}$ in this study when renal function was assessed by the MDRD equation, but not by $\mathrm{C}-\mathrm{G}$. This is in agreement with the findings of the UK and Sweden studies when using the MDRD [19,22], but not with the Japanese's study, in which the male gender was reported to be a non-modifiable risk factor for CKD [20]. Furthermore there was a strong association between female sex and CKD in the UK and Sweden studies using C-G equation [22,23]. The possible explanation for this might be due to the higher proportion of obese females than males and the equation being adjusted for BSA in this study, in which the C-G adjusted for BSA overestimated GFR in diabetics with obesity [25].

As expected, there was a significant association between CKD and the presence of longer duration of diabetes and a family history of kidney disease in this study subjects using either the MDRD or C-G equation. This corresponds with the findings of several studies, which reported that the like hood of developing reduced eGFR was greater among patients with longer duration of diabetes and among those with or whose parents has kidney disease [19,20,22].

This study also found a significant association between obesity and CKD when renal function was assessed by the MDRD equation, but not by $\mathrm{C}-\mathrm{G}$. This corresponds with the findings of two different UK studies using a similar definition of eGFR [20,22]. However, low BMI was independently associated with $\mathrm{CKD}$ by $\mathrm{C}-\mathrm{G}$ in the $\mathrm{UK}$ study [22]. This might be explained by the $\mathrm{C}-\mathrm{G}$ equation used in this study, which is adjusted for BSA [25]. A significant association between Type 2 diabetes and CKD was found in the study subjects when $\mathrm{C}-\mathrm{G}$ equation was used to define renal function, but not by the MDRD. Similarly, the UK and Japanese studies reported that Type 2 diabetes was not associated with CKD when using the MDRD equation [19,20].

In this study, uncontrolled diabetes corresponding to high fasting serum glucose was associated with CKD when defined by either equation; in contrast with findings that identified patients with CKD (eGFR $<60 \mathrm{ml} / \mathrm{min} / 1.73 \mathrm{~m}^{2}$ ) had better glycaemic control $[19,20]$. However, our finding corresponds with the current guidelines reported that the prevalence of kidney disease was fivefold greater among patients with uncontrolled diabetes compared with controlled [3,12]. This is attributed to the early development of end-organ damage and late presentation for medical care in patients with poorly controlled diabetes.

Hypertension and elevated systolic blood pressure were not independently associated with CKD when renal function was defined by either equation in this study. It showed that the presence of elevated systolic BP was a significant risk factor for CKD by univariate analysis but not by multivariate analysis, and this was in contrast with other related studies, in which elevated systolic BP was independently associated with CKD when defined by the MDRD [19,22] or C-G equations [22,23]. The beneficial effects of controlling blood pressure and using antihypertensive agents on kidney function in diabetics has been described repeatedly in current guidelines [3,12].

Although this study is the first of its type in Ethiopia, it has a few limitations. First, it is limited by the fact that the $\mathrm{K} / \mathrm{DOQI}$ proposed using eGFR and albuminuria to evaluate and classify the stages of $\mathrm{CKD}$, were lack of information regarding albuminuria made it difficult to confirm whether patients with $\mathrm{eGFR} \geq 60 \mathrm{ml} / \mathrm{min} / 1.73 \mathrm{~m}^{2}$ were having CKD or not. Second, calculated GFR rather than measured GFR was used to diagnose renal insufficiency and the MDRD equation used in this study is not validated among adult populations of Ethiopian origin. The other limitation of this study is that the data are cross-sectional, not longitudinal, preventing assessment of whether risk factors caused or resulted from CKD. Moreover, due to the relatively small samples in this study, associations between different severity levels of CKD have not been studied. Follow-up data are required on how the identified associations with decreased eGFR predict clinical outcome. Our study also has major strengths, including the diagnosis of CKD based on eGFR on multiple measures to establish chronicity, and the provision of CKD within a high-risk group, a reliable scenario of the current diagnostic approach for targeted screening of CKD in primary care.

\section{Conclusion}

In conclusion, the study identified a high prevalence of CKD (ranging from 18.2-23.8\% depending on the formula used to estimate GFR) among diabetic adults attending Butajira hospital of southern Ethiopia. Risk factors for CKD such as ageing, longer duration of diabetes and poorly controlled diabetes were similar to those reported in developed country studies. This study, therefore, proposes that a nationwide survey to be conducted encompassing the entire diabetes population to find out the prevalence of $\mathrm{CKD}$ and its associated risk factors, so that a preventive strategy or an entire defensive framework could be adopted or planned to reduce the disease and complications related to it in the community.

\section{Acknowledgements}

We are grateful to acknowledge Jimma University College of Public Health and Medical Sciences for providing financial assistance for the study. We also like to acknowledge data collectors and administrations of the Butajira hospital. Finally, we gratefully thank the study participants.

\section{References}

[1] Levey AS, Eckardt KU, Tsukamoto Y, Levin A, Coresch J, Rossert J. Definition and classification of chronic kidney disease:a position statement from Kidney Disease: Improving Global Outcomes (KDIGO). Kidney Int. 2005;67(6):2089-100. 
[2] Wali RK. Aspirin and the prevention of cardiovascular disease in chronic kidney disease: time to move forward? J Am Coll Cardiol. 2010;56:966-8.

[3] National Kidney Foundation. K/DOQI Clinical Practice Guidelines for Chronic Kidney Disease: Evaluation, Classification, and Stratification. Ann Intern Med. 2002;39(2):S1-266.

[4] International Diabetes Federation. Diabetes at a glance,2012;IDF Diabetes Atlas,5th ed. International Diabetes Federation, Brussels; 2012.

[5] Atkins RC, Zimmet P. World Kidney Day 2010: Diabetic Kidney Disease - Act Now or Pay Later. Am J Kidney Dis. $2010 \mathrm{Feb} ; 55(2): 205-8$.

[6] Ninomiya T, Perkovic V, de Galan, Zoungas S, Pillai A, Jardine $\mathrm{M}$, et al. Albuminuria and kidney function independently predict cardiovascular and renal outcomes in diabetes. J Am Soc Nephrol. 2009;20:1813-21.

[7] Go AS, Chertow GM, Fan D, McCulloch CE, Hsu C. Chronic Kidney Disease and the Risks of Death, Cardiovascular Events, and Hospitalization. N Engl J Med. 2004;351(13):1296-305.

[8] McGovern AP, Rusholme B, Jones S, Vlymen JN van, Liyanage $\mathrm{H}$, Gallagher $\mathrm{H}$, et al. Association of chronic kidney disease (CKD) and failure to monitor renal function with adverse outcomes in people with diabetes: a primary care cohort study. BMC Nephrol. 2013;14:198.

[9] National Kidney Foundation. KDOQI Clinical Practice Guidelines and Clinical Practice Recommendations for Diabetes and Chronic Kidney Disease. Am J Kidney Dis. 2012 Feb;49(2):S12-S154.

[10] Grandfils N, Detournay B, Attali C, Joly D, Simon D, Vergès $B$, et al. Glucose Lowering Therapeutic Strategies for Type 2 Diabetic Patients with Chronic Kidney Disease in Primary Care Setting in France: A Cross-Sectional Study. Int J Endocrinol [Internet]. 2013; Available from: http://dx.doi.org/10.1155/2013/640632

[11] Yadav SCB. Glycemic control in diabetic kidney disease patients. Clin Queries Nephrol. 2012 Apr;1(2):111-4.

[12] American Diabetes Association. Standards of medical care in diabetes - 2011. Diabetes Care. 2011;34(Supp 1):S11-S61.

[13] Manns B, Hemmelgarn B, Tonelli M, Flora Au, Chiasson TC, Dong J, et al. Population based screening for chronic kidney disease: cost effectiveness study. BMJ. 2010;34:c5869.
[14] Levey A, Greene T, Kusek J, Beck G. A simplified equation to predict glomerular filtration rate from serum creatinine. $\mathrm{J}$ Am Soc Nephrol. 2000;11:A0828.

[15] Cockcroft DW, Gault MH. Prediction of creatinine clearance from serum creatinine. Nephron. 1976;16:31-41.

[16] KDIGO conference proposes changes to CKD classification, but not to the definition. Nephrol. 2009;2(12):9-10.

[17] Coresh J, Astor BC, Greene T, Eknoyan G, Levey AS. Prevalence of chronic kidney disease and decreased kidney function in the adult US population: Third National Health and Nutrition Examination Survey. Am J Kidney Dis. $2003 ; 41: 1-12$.

[18] New JP, Middleton RJ, Klebe B, Farmer CKT, De Lusignan $\mathrm{S}$, Stevens PE, et al. Assessing the prevalence, monitoring and management of chronic kidney disease in patients with diabetes compared with those without diabetes in general practice. Diabet Med. 2007;24(4):364-9.

[19] Middleton RJ, Foley RN, Hegarty J, Cheung CM, McElduff $\mathrm{P}$, Gibson JM, et al. The unrecognized prevalence of chronic kidney disease in diabetes. Nephrol Dial Transplant. 2006;21(1):88-92.

[20] Ohta M, Babazono T, Uchigata Y, Iwamoto Y. Comparison of the prevalence of chronic kidney disease in Japanese patients with Type 1 and Type 2 diabetes. Diabet Med. 2010;27(9):1017-23.

[21] Janmohamed MN, Kalluvya SE, Mueller A, Kabangila R, Smart LR, Downs JA, et al. Prevalence of chronic kidney disease in diabetic adult out-patients in Tanzania. BMC Nephrol. 2013;14(183).

[22] Afghahi H, Cederholm J, Eliasson B, Zethelius B, Gudbjörnsdottir S, Hadimeri H, et al. Risk factors for the development of albuminuria and renal impairment in type 2 diabetes - the Swedish National Diabetes Register (NDR). Nephrol Dial Transpl. 2011;26:1236-43.

[23] Retnakaran R, Cull CA, Thorne KI, Adler AI, Holman RR. Risk Factors for Renal Dysfunction in Type 2 Diabetes U.K. Prospective Diabetes Study 74. Diabetes. 2006;55(6):18329.

[24] Garg AX, Kiberd BA, Clark WF, Haynes RB, Clase CM. Albuminuria and renal insufficiency prevalence guides population screening: results from the NHANES III. Kidney Int. 2002;61:2165-75.

[25] Jesudason, P Clifton. Interpreting different measures of glomerular filtration rate in obesity and weight loss: pitfalls for the clinician. Int J Obes. 2012;36:1421 - 1427. 